\title{
TAKOKAK “HOROR “ PENINGGALAN PERANG DUNIA II DAN KELAHIRAN TOKOH REFORMIS DUNIA
}

\author{
Muhammad Daud Yusuf \\ muhammad.dy2019@gmail.com \\ Indra Kristian \\ $\underline{\text { Technician2007@gmail.com }}$
}

\begin{abstract}
Abstrak
Takokak adalah sebuah wilayah yang berada di Kabupaten Cianjur berbatasan dengan Sukabumi, Propinsi Jawa Barat. Secara administratif Kecamatan Takokak berbatasan dengan Kecamatan Nyalindung dan Kecamatan Purabaya Kabupaten Sukabumi di sebelah barat, Kecamatan Gegerbitung Kabupaten Sukabumi di utara, Kecamatan Sukanagara Kabupaten Cianjur di timur, dan Kecamatan Kadukapandak Kabupaten Cianjur di selatan. Dari Komunitas Budaya Sunda yakni tim Kombucriper (Komunitas Budaya Cinta Ritual Pertanian) suatu komunitas diskusi ilmiah budaya yang berkantor di Kabupaten Bandung Barat Jawa Barat mencoba menelusuri jejak tradisi budaya Sunda di Takokak, dengan cara nyucruk galur mapay laratan karuhun dinataranya menelusuri jejak Bisri Artha Winata, tokoh Sunda yang fenomenal yang berasal dari Takokak, dan Pengusaha nasioanl Tomy Winata, anak Takokak. Awalnya penulis hanya ingin ngembang atau nadran alias berziarah ke makam kakek buyut penulis yang bernama Ki Ading yang konon ia merupakan tukang boboko dari Majalaya Bandung, namun di balik bobokonya ia ditugaskan memasok senjata kepada rekan-rekannya sesama pejuang yang diataranya Bisri Artha Winata di Takokak.Konon Ki Ading atau Mayor Ading (Eyang Udas) pada zamannya diwajibkan ikut sebagai pejuang kemerdekaan negeri ini, namun konon ia gugur, sahid bersama ribuan teman dan anak buahnya di medan juang bahkan banyak yang tertangkap tentara Belanda dan dibawa ke Gunung Tugu daerah Takokak untuk di eksekusi mati, tak kembali lagi. Eksekusi para pejuang Takokak di kaki Gunung Tugu terjadi pada masa perjuangan kemerdekaan melawan penjajah Belanda.Konon yang selamat waktu itu hanya satu orang tentara pejuang yang bernama Bisri Artha Winata itupun konon karena hanyut bersama aliran darah para pejuang yang mengalir ke kali Cikawung di kaki Gunung Tugu. Sehingga menurut kepercayaan masyarakat setempat yang merupakan tokoh jawara legendaris mereka di Takokak melawan penjajah Belanda diantaranya Bisri Artha Winata. Ia merupakan tokoh pejuang asal Sunda Takokak yang paling di cari tentara Belanda waktu itu. Namun setelah merdeka Lurah Bisri Artha Winata sempat menjabat sebagai Jaro alias Kepala Desa Takokak dengan julukan Lurah Bisri.
\end{abstract}

Kata Kunci:Takokak-Tokoh-Legendaris-Dunia. 


\section{Latar Belakang Penelitian}

Dulu katanya, truk-truk dan tank baja tentara Belanda di bawah komando Westerling bisa sampai ke Desa Takokak. Toh juga, selain memang tujuannya membantai pendukung NKRI, juga kepentingan Belanda pada jaman itu melakukan tanam paksa komodti pertanian berupa bahan rempah: Kopi, cengkeh, teh dan kina. Karena kontur dataran Takokak di Cianjur Selatan perbatasan Sukabumi ini berbukit-bukit dan berhawa dingin, jadi surga bagi Belanda untuk memaksa semua penduduk menanam komoditi paling menguntungkan pada zaman itu.

Dengan adanya Taman Makam Pahlawan Gunung Tugu di taman inilah kita melihat berjajar rapi makam-makam pahlawan tanpa nama. Mereka pahlawan pejuang yang melawan tentara Belanda dan juga korban pembantaian oleh tentara Belanda karena merekalah dianggap kaum republikan atau kaum Sukarnoisme.

\section{Kajian Pustaka}

\subsection{Tomi Winata Tokoh Pengusaha Nasional Legendaris, Merupakan Anak Takokak}

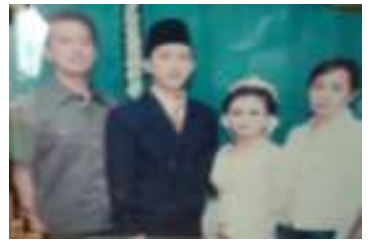

Poto:Tomi Winata waktu muda dan Keluarga di Takokak

Penulispun sempat menemui tokoh setempat yakni Ustad Lili di Takokak, yang mana ustad tersebut mempunyai kedekatan dengan Cecep Winata putra Bisri Artha Winata di Kampung Kadang Sapi di Takokak. Cecep merupakan putra sulung Bisri Artha Winata, yang juga ia konon merupakan kakak dari Tomy Winata bos pengusaha Artha Graha Group Sembilan Naga yang fenomenal,ia sang pengusaha nasional Indonesia keturunan Cina yang sukses dikancah internasional urutan ke 40 terkaya didunia versi Majalah Forbes, yang konon pebgusaha ini di besarkan di Takokak atau anak Takokak yang kemudian sukses menjadi bisnisman terkenal. Atas rekomendasi Cecep Winata penulispun sempat menyambangi Rumah Tomy Winata yang dijaga oleh para anak buah Bos Tomi ini di Jalan Datar Takokak dan penulispun menyempatkan diri untuk berziarah kemakam Bisri Arta Winata yang terletak 
dipelataran gedung rumah Bos Tomy Winata ini, yang merupakan rumah peninggalan Bisri Arta Winata orang tuanya.Tomy Winata sering dikenal dengan inisial TW, adalah seorang pengusaha Indonesia keturunan Tionghoa yang merupakan pemilik Grup Artha Graha atau Artha Graha Network. Usahanya terutama bergerak dalam bidang perbankkan, properti dan infrastruktur. Disamping usaha bidang komersil, Tomy Winata juga dikenal sebagai pendiri Artha Graha Peduli, sebuah yayasan sosial, kemanusiaan dan lingkungan. Bank Propelat lalu diubah namanya menjadi Bank Artha Graha oleh Tomi Winata. Sejarah bank ini dimulai sejak 1987. Menurut Sam Setyautama, TW punya orang tua angkat di Sukabumi, seorang lurah di Desa Takokak, bernama Bisri Arthawinata. Tak mengherankan jika Tommy menyandang nama Winata dan Artha menjadi nama depan banknya dan nama perusahaanperusahaan milik TW lainnya.

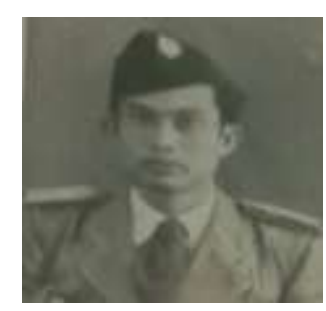

Bisri Arta Winata, Tokoh Sunda Legendaris di Takokak

Bisnis TW tentu saja bukan bank dan konstruksi saja. Di bidang properti, pada era 2000-an, seperti dicatat Sam Setyautama, setidaknya TW punya Agung Sedayu Metro Development, Agung Sedayu Propertindo, Arthayasa Grahatama, Garuda Mega Harapan, Jakarta Graha Sentosa, dan Citra Laksana Graha Prima. Di bidang kontruksi: Agung Sedayu Permai, Arthayasa Adiprima, dan Graha Mulya Nusa. Di bidang telekomunikasi ada Danatel Pratama. Di bidang elektronik ada Artha Graha Wahana. Sementara di sektor perikanan ada Ting Sheen Bande Sejahtera. TW juga menjadi salah satu pemilik Hotel Borobudur Internasional. Grup Artha Graha, yang dipimpin TW sebagai salah satu konglomerat penting Indonesia, telah membawahi 40 perusahaan.

\subsection{Nama Mahdi Pemberian Dari Bung Karno Kepada Anak KelahiranTakokak}

Nama Mahdi pemberian Bung Karno, persiden RI pertama kepada sang satria kecil yang baru lahir di Takokak.Selain itu dalam kepercayaan warga setempat mengenai kisah tentang Satria Piningit alias Ratu Adil alias yang disebut Imam Mahdi Al-Muhtadhor alias 
Muhammad alias Purta Siti Aminah, alias budak angon ti Legok Cawene (papagon Sunda uga Prabu Siliwangi), alias Kholifatullah Mahdi, ia konon berasal dari Takokak pula, ia bukan presiden, tetapi kholifatullah (Raja), tentunya raja berbeda dengan presiden. Sudah pada tahu kalau Presiden RI sekarang ya Jokowi Presiden pilihan rakyat, kalau kholifatullah ya Raja Indonesia pilih Allah SWT yakni Imam Mahdi. Hal ini sesuai jika mengacu kepada serat pusaka amarasulillah yang diberikan dari Bung Karno kepada Muhammad zaman now alias Imam Mahdi alias Ratu Adil usai upacara penobatan Imam Mahdi sebagai Raja Indonesia oleh Bung Karno yang hadiri 320 orang perwakilan dari berbagai negara bertempat di lapangan upacara Istana Bogor tahun 2004, pada serat pusaka tersebut bertuliskan "Pangeran Didi Raja Indonesia la illaha ilalloh Muhammadarrosulullah " nama Didi ialah nama neneh (panggilan) dari Mahdi waktu kecil, nama Muhammad bin Abdullah telah ada dalam Qur'an kata Imam Mahdi artinya pemimpin yang memberi petunjuk. Hal ini tercamtum dalam Firman Allah di dalam Qur'an "Dan Kami jadikan diantara mereka itu pemimpin-pemimpin yang memberi petunjuk dengan perintah Kami, ketika mereka bersabar (Q.S As-Sajdah:24), dan telah dijelaskan oleh hadist-hadist Rasulullah dalam Sabda Nabi Muhammad SAW bahwa: Walaupun tersisa hanya sehari saja dari umur dunia ini pastilah Allah akan mengutus seorang lelaki dari ahlil baitku, dia akan memeratakan keadilan di bumi ini.Ia akan menjadi raja selama tujuh, delapan atau sembilan taun, Mahdi itu namanya sama namaku, nama Bapaknya sama dengan nama Bapakku (Muhammad bin Abdullah), Mahdi akan datang dari timur (maksudnya Indonesia). (HR.Abu Dawud). Nama Mahdi (diwasalkan) diberikan oleh Bung Karno ketika sang satria ini masih kecil. Imam Mahdi diyakini juga merupakan tokoh legendaris dunia yang ditunggu-tunggu oleh berbagai agama besar dunia.Satria ini bernama Muhammad yang menurut kepercayaan masyarakat setempat juga berasal dari Takokak.Makam Haji Abdullah Bapaknya Muhamad zaman now (Ratu Adil) alias Prabu Brajawijaya Buanangalaga Kusumahdiningrat ini makan ayahnya satria tersebut, juga berada di Takokak dan makam Ibunya Muhammad jurnalis alias Muhammad zaman now ini yakni Hj. Siti Aminah terletak di Takokak juga.Makam kelurganya yakni makam Haji Ali, Hj.Siti Fatimah, Hj.Siti Aisyah, Hj.Siti Asiah juga berjejer berdekatan dengan makam Haji Abdullah juga berada di Takokak.

Kita ketahui NKRI secaca konstitusi berdasarkan Undang-Undang Dasar 1945 berbentuk republik, artinya bukan kerajaan.Ini menunjukan Imam Mahdi raja di alam republik, jika kehadiran Imam Mahdi masih kontroversi dengan Undang-Undang, mana bisa ? Mungkinkah Takokak kedepan menjadi Kota Mekahnya Indonesia kalau Muhammad zaman now yang 
disebut Imam Mahdi oleh Nabi Muhammad SAW sudah di imani di Indonesia ? Ataukah Republik Indonesia akan seperti negeri Kan'an zaman Nabi Nuh AS dihancurkan oleh Allah dengan bala bencana alam ? Akibat bangsanya tidak mau mengakui Imam Mahdi sebagaimana yang diperintahkan oleh Nabiyullah Rasulullah Muhammad SAW ? Wallahu a'lam, kalau sombong baredegong bala bencana moal ereun, buktikan saja, kalau kita masih tersisa atau belum habis dengan bencana alam.

\subsection{Pernyataan Para Ulama dari Kota Mekah dan Madinah Arab Saudi}

Hal ini sesuai dengan pernyataan para ulama dari Kota Mekah dan Madinah sejumlah ulama berpendapat untuk mempertegas keyakinan akan kemunculan seorang mujaddid (pembaru) pada abad peralihan (zaman now), ia adalah Imam Mahdi yang akan muncul pada abad milenium ini (2003). Ibnu Al-Hajar menyatakan, Imam Mahdi itu berasal dari keturunan Sayidina Ali-Fatimah, putri Nabi. Namanya akan sama dengan nama Nabi, serta orangtuanya sesuai dengan nama orangtua Nabi, yakni Imam Mahdi itu namanya Muhammad bin Abdullah dan nama ibunya bernama Siti Aminah, sama dengan nama ayah itu Nabi Muhammad SAW. Ia juga merupakan tokoh legendaris dunia yang ditunggu-tunggu oleh berbagai agama besar dunia. Banyak tokoh agama dan aliran kepercayaan meyakini kedatangan seorang juru selamat dan reformis global, akan membawa masa depan yang cerah bagi umat manusia.Dalam keyakinan Islam akan datangnya sang juru selamat lebih mengakar, lebih realistis, dan didukung oleh teks-teks agama dalam Kitab Suci Al-Qur'an dan Hadist. Berdasarkan berbagai riwayat, Imam Mahdi as berasal dari keturunan Rasulullah Saw dan dengan kedatangannya, ia akan menumpas orang-orang zalim dan membangun sebuah pemerintahan global yang berbasis pada perdamaian, keadilan, dan penegakan nilainilai agama.Rasulullah Saw bersabda, "Aku sampaikan kabar gembira kepada kalian dengan datangnya al-Mahdi yang akan bangkit ketika manusia sedang dilanda perselisihan dan kegoncangan hebat. Dia akan memenuhi bumi dengan kejujuran dan keadilan sebagaimana sebelumnya bumi dipenuhi dengan penindasan dan kezaliman." (HR.Abu Daud). 


\subsection{Bangsa Indonesia Disudutkan dalam Perjanjian Renville}

Dari sejarah Perjanjian Renville, dari situasi yang terus menyudutkan ini, Belanda akhirnya meminta perundingan di atas kapal perang Amerika. Perjanjian yang akhirnya dikenal sebagai Perjanjian Renville ini berlangsung dengan cukup alot. Di perundingan ini, Belanda hanya mengakui wilayah Indonesia di kawasan Jawa Bagian Tengah, Banten, dan Sumatra. Perjanjian tersebut membuat militer Indonesia harus menarik kekuatannya dari Jawa Barat dan Jawa Timur.Setelah tentara Jepang angkat kaki dari Indonesia, peralatan tempur militer yang mereka miliki praktis diambil alih oleh militer Indonesia. Peralatan perang hasil jarahan ini akhirnya digunakan kembali untuk alat membela diri oleh para pejuang saat Belanda masuk lagi ke Indonesia. Senjata yang dimiliki oleh pihak militer Indonesia itu membuat Belanda dan sekutunya kalang kabut. Pasalnya sebelum Belanda kalah oleh Jepang, kekuatan persenjataan dari Indonesia tidak sehebat itu.

Permintaan yang merugikan pihak Indonesia ini tentu saja tidak serta merta disetujui. Jenderal Sudirman yang kala itu menjadi pemimpin TNI masih mengusahakan kekuatan ada di kawasan Jawa Barat apa pun caranya. Akhirnya, beberapa pasukan menyamar menjadi pasukan liar yang terpisah dengan kaum republiken yang menginginkan Indonesia merdeka secara utuh.Terjadilah perburuan kaum Republiken. Apa yang dilakukan oleh pasukan Indonesia ini sebenarnya diketahui oleh militer Belanda. Terlebih lagi, pasukan republiken yang menyamar ini kerap menyerang pos militer di daerah kekuasaan Belanda. Akhirnya Belanda berang dan melakukan perburuan kepada kaum-kaum republiken yang disinyalir kerap membuat keributan dan menyerang militer Belanda secara diam-diam. 


\subsection{Pembantaian Oleh Westerling Tentara Belanda Terhadap Pejuang Takokak}

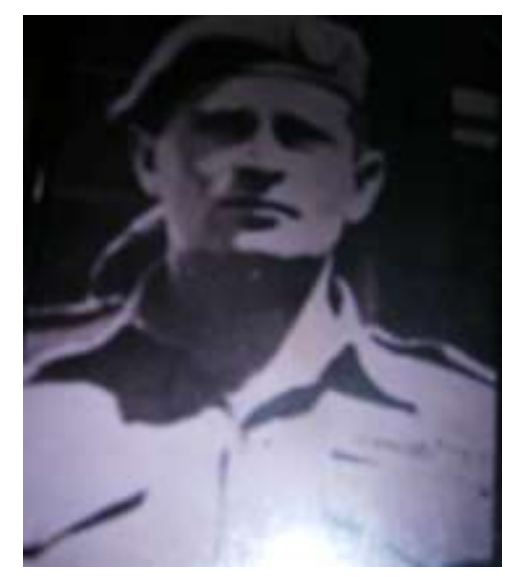

Westerling:Tentara Belanda

Dari beberapa saksi mata yang melihat kejadian, tentara Belanda kerap melakukan tindakan pembantaian sadis. Orang republiken yang ditangkap langsung dieksekusi begitu saja dibantai tampa pri kemanusiaan. Setelah dieksekusi, mayat mereka dibiarkan berserakan begitu saja di di kebun teh dan jurang tidak jauh dari Takokak. Selain di kawasan ini, pembantaian juga di lakukan di beberapa tempat seperti di Ciwangi, Gamblok, Cikawung, dan Pasirtulang. Kawasan Takokak sudah menjadi kawasan pembunuhan masal yang diketahui banyak orang. Sayangnya, tidak orang yang berani mengungkap kala itu karena khawatir nyawa mereka bisa ikut melayang dengan cepat.Bagi penduduk di kawasan Jawa Barat khusus Cianjur, kalau ada orang yang dibawa militer Belanda ke Takokak, dia tidak akan pernah kembali.

Wilayah Takokak merupakan pegunungan dan dataran tinggi sehingga penduduk di wilayah ini sebagian besar bermata pencaharian sebagai petani, mereka mengelola perkebunan sayur dan kebutuhan pangan lainnya. Sebagian besar hasil pertaniannya didistribusikan ke Kabupaten dan Kota Sukabumi, Jakarta dan hanya sebagian kecil ke Kabupaten Cianjur. Hasil pertanian dari wilayah ini berupa sayuran, beras, dan teh. 


\subsection{Di Takokak Kini Terdapat Beberapa Destinasi Wisata}

Di Takokak terdapat beberapa destinasi wisata diantaranya:

1) Taman Makam Pahlawan Cigunung Tugu

2) Perkebunan Teh Bungamelur

3) Perkebunan Teh Cisujen

4) Perkebunan Teh Cikarang

5) Telaga Ciukur

6) Situ Ole (Telaga)

7) Curug Sumpit

8) Curug Simpang

Di Takokak wisata mancing di Situ Gunung Tugu sudah menjadi tradisi Sunda Tatar Pakidulan Takokak baru-baru ini.Takokak sebuah Kecamatan bersejarah di Kabupaten Cianjur sebelah selatan, termasuk daerah tatar Sunda pegunungan yang letaknya didekat perbatasan antara Kabupaten Sukabumi dan Kabupaten Cianjur kawasan pedesaan sebelah selatan Jawa Barat. Daerah ini sangat sejuk cocok untuk berwisata keluarga selain sejuk juga indah daerah ini warganya dikenal akuan (ramah terhadap tamu). Daerah ini banyak mengasilkan sayur-mayur dan perkebunan teh hijau, bahkan para komlomerat negeri ini banyak yang memiliki perkebunan teh di daerah ini, seperti halnya kongmerat dari grup sembilan naga, Tommy Winata memiliki perkebunan teh yang cukup luas di daerah ini.Waktu itu awal tahun 2020 penulis berangkat dari Bandung, lewat Terminal Pasir Hayam Cianjur arah selatan melewati Campaka dan Sukanagara, menempuh jarak Bandung Takokak sekitar 114 KM selama sekitar 5 jam.Diperjalanan melewati hamparan perkebunan teh yang indah membentang sejauh mata memandang milik perusahaan Teh Botol Sostro. Penulispun sempat berhenti sejenak buat berpoto selfi di tengah areal perkebunan teh lainnya, memang sudah tersedia saung-saung kebun teh dipinggiran jalan yang dilewati, di daerah itu maryarakat setempat menyebutnya kampung Situ Wangi.

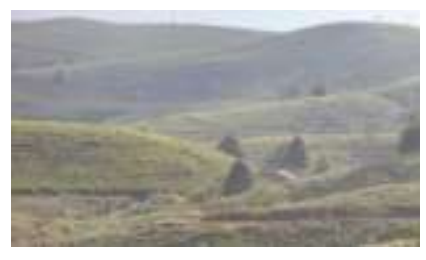

Perkebunan Teh di Takokak 
Selain teh dari kawasan ini dikenal sebagai penghasil sayur-mayur Takokak yang berkualitas, dari daerah Takokak menurut Edi Mulyadi, Ketua Koprasi Unit Desa (KUD) Takokak penampung, koprasinya bisa memasok rata-rata 16-30 truk sayur-mayur perhari ke Jakarta melalui pasokan lapak Pasar Cibitung Bekasi. Para petani Takokak berasal dari Majalaya, Lembang, Ciwididey dan Panglengan dari daerah Bandung banyak di temukan hijrah kedaerah ini untuk mengembangkan usaha taninya di Takokak. Menurut Zaenudin perusahaan nasional juga seperti PT. Indofood Sukses Makmur, Teh Sostro, Arta Graha dll konon mengembangkan usaha perkebunannya di Takoakak. Bahkan pengusaha nasional Arifin Panigoro menurut Ujang Suhandi warga setempat sedang membangun bendungan PLTA Cibeber di Takokak.

\subsection{Orang Yang Dibawa ke Takokak Oleh Serdadu Belanda, dieksekusi Tak Kembali Lagi Untuk Selamanya}

Enampuluh delapan makam tak bernama itu bernisan putih.Hampir semua orang Takokak tahu, bahwa yang dikuburkan di Bukit Cigunung Putri itu adalah korban-korban pembantaian Belanda zaman perang dulu.Dan memang, sudah sejak 1947, Takokak dikenal sebagai pusat eksekusi orang-orang Indonesia dari wilayah Sukabumi dan Cianjur, sejak sebagian besar anggota Divisi Siliwangi hijrah ke Yogyakarta dan Jawa Tengah pada awal 1948, pembantaian-pembantaian itu semakin menggila terjadi di Takokak.Jadi jika dulu ada seseorang yang dibawa ke Takokak, maka sudah bisa dipastikan ia tak akan kembali lagi, ujar mantan anggota lasykar yang pernah bertugas di Takokak . Tempat eksekusi mati di Takokak di antaranya di Jalan Lima, Puncak Bungah, Ciwangi, Pal Dua, Pasirtulang dan Cikawung. Seorang saksi mata Yusup sendiri bahkan pernah menyaksikan sekaligus mengevakuasi lima mayat korban eksekusi di Ciwangi. Rata-rata mereka tewas dengan sebuah lubang peluru di tengkuknya masing-masing.Atjep sebagai seorang eks tentara mengatakan mereka yang dieksekusi di Takokak mayoritas adalah orang-orang sipil, mereka sebelumnya dibon (diambil) dengan truk-truk militer dari penjara Van Delden di Gunung Puyuh, Sukabumi, seperti dikatakan Ketua Legiun Veteran Republik Indonesia (LVRI) rayon Takokak itu.

Sesampainya di Takokak, para tahanan itu disimpan dahulu di kantor kecamatan atau pos militer Belanda di Bunga Melur. Lantas setelah satu atau dua jam, mereka baru dibawa ke beberapa titik yang sudah disebutkan di atas untuk dihabisi. Pimpinan algojonya seorang 
Belanda totok, namanya dikenal orang-orang Takokak saat itu sebagai Si Werling, orangnya kekar tidak begitu tinggi dan sering pakai baret berwarna hijau. Tragedi Takokak 1948, Pembantaian Rakyat Indonesia oleh Belanda yang Terlupa.

Sejarah mencatat kalau Belanda masih melakukan tindakan pembantaian secara keji setelah Indonesia melakukan Proklamasi Kemerdekaan pada tahun 1945. Pasca Jepang mengaku kalah kepada sekutu, Belanda kembali lagi dengan bantuan tentara sekutu seperti Inggris untuk merebut kembali negeri yang mereka keruk sumber dayanya selama ratusan tahun.

Selama kembali lagi ke Indonesia, Belanda telah beberapa kali melakukan pembantaian yang dikutuk oleh dunia internasional. Pertama adalah pembantaian yang dilakukan oleh Westerling pada akhir tahun 1946 di Sulawesi Selatan. Kekejaman Westerling pada aksi ini mendapat protes banyak pihak di Belanda. Pembantaian selanjutnya terjadi di kawasan Peniwen, Malang yang menyebabkan beberapa anggota PMR tewas dan memicu banyak protes di Eropa.

Selain dua pembantaian yang telah disebutkan sebelumnya, ada satu lagi peristiwa yang tidak kalah menyeramkan (horor) di daerah Takokak, Jawa Barat, kaum republiken dibantai dengan keji dan mayatnya langsung dibuang ke jurang. Mereka diburu, dicekal, lalu ditembaki dengan membabi buta hingga tidak bernyawa. Berikut uraian lengkap tragedi Takokak 1948 yang mengerikan itu.Ditengah perjalanan di pedesaan Takokak terletak sebuah gunung yang rindang dengan pepohonan kayu rasamala, masyarakat setempat menyebutnya Gunung Tugu dibawahnya ada situ masyarakat setempat menyebutnya Situ Gunung Tugu di Cikawung Takokak. Konon sekitar tahun 1980 -an dari gunung tersebut ditemukan ribuan tengkorak dan tulang belulang manusia, katanya tulang belulang para pejuang kemerdekaan yang bertempur melawan Belanda waktu zaman perjuangan, saking banyaknya yang gugur sehingga tengkorak dan tulang belulangnya menggunung di tengah hutan gunung tersebut.Konon tengkorak dan tulang-tulang tersebut setelah ditemukan kemudian diangkut dengan truk- truk oleh petugas untuk dikuburkan di pinggir jalan di kaki gunung Tugu, yang kemudian dinamakan Taman Makam Pahlawan Desa Pasawahan Kecamatan Takokak, taman makam tersebut bersebelahan dengan Situ Gunung Tugu di kampung Cikawung Desa Pasawahan Kecamatan Takokak. 


\subsection{Taman Makam Pahlawan Gunung Tugu Takokak Cianjur Sealatan}

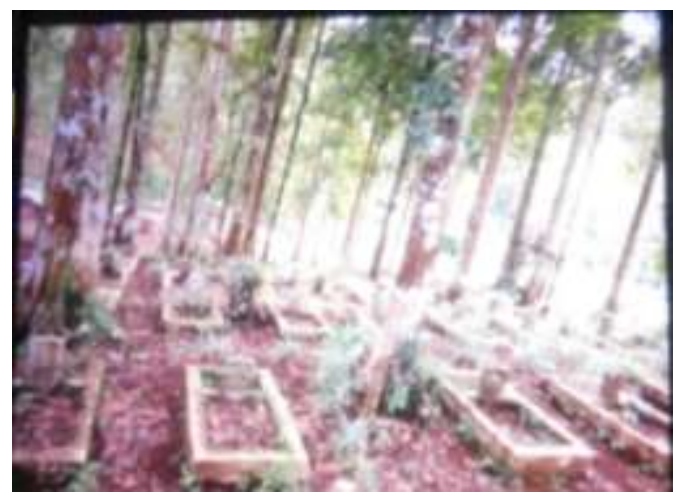

Karena lokasinya sangat terasing inilah, wilayah ini pada zaman Belanda dijadikan tempat pembantaian kaum pendukung NKRI alias republikan. Konon, simpatisan NKRI ini dari beberapa spot wilayah Sukabumi, Nyalindung, Sagaranten dan sekitarnya, ditangkap Belanda dan dibawa ke hutan di Gunung Malang. Di hutan inilah mereka dibantai tentara Belanda,mereka dibantai di Puncak Bungah, juga tempat pembantaian kaum pro NKRI atau pro Soekarno atau zaman itu mereka menyebutnya Kaum Republikan.

Menurut sejarah yang tidak pernah ada dalam catatan pemerintahan Indonesia, salah satu pembantaian mengerikan yang dilakukan oleh Belanda, terjadi di kaki Gunung Tugu, Desa Takokak, Kecamatan Cianjur Selatan. Perbatasan Sukabumi - Cianjur Selatan. Secara lokasi strategisnya, harusnya masuk wilayah Sukabumi, tetapi entah kenapa, kecamatan ini masuk wilayah Cianjur Selatan dan tidak pernah pun disentuh oleh pemerintahan Cianjur. Lokasinya memang lebih menguntungkan Sukabumi dan penduduk di kaki Gunung Tugu, soalnya hasil pertanian lebih dekat dijual ke Sukabumi dibandingkan harus jauh menempuh jalan menuju kota Cianjur.

Di dekat taman makam pahlawan tak dikenal tersebut, dari sekitar gunung tersebut mengalir air sungai yang jernih, yang membentuk danau atau situ yang dikelola Jajang, pensiunan TNI beserta istrinya. Orang-orang suka memancing di situ gunung Tugu ini,disana disediakan juga rakit-rakit dan saung-saung lesehan untuk berwisata santai sambil mengenang sejarah perjuangan para pejuang Sunda yang telah gugur di medan perang melawan penjajah Belanda, mereka telah berkorban untuk memperjuangkan kemerdekaan negeri ini. Nah, kembali ke pembantaian di Takokak, ketika zaman perang, banyak Belanda gila. Mereka kalau nembak membabi-buta. Menurut cerita para pejuangan veteran, pembantaian tidak hanya dilakukan diperkebunan,hutan atau jurang-jurang di sekitaran Takokak. Pembantaian 
dilakukan di Ciwangi, Pal I Cengang, Gamblok, Cikawung dan Pasir Tulang.Kenapa penduduk menyebutnya Pasir Tulang, karena memang di sini dijadikan bukit pembantaian para pejuang.

Sekarang,untuk mengenang jasa para pahlawan, setiap memperingati hari kemerdekaan 17 Agustus, seluruh Sekolah SMP di Cianjur Selatan, khususnya perbatasan Sukabumi, pergi ke Taman Makan Pahlawan Gunung Tugu dan berziarah sambil berdo'a, membersihkan rumput-rumput liar di atas makamnya.

Kembali mengingat sejarah, hingga akhirnya Indonesia merdeka secara de jure pasca Konfrensi Meja Bundar, dalang dari pembantaian di Takokak 1948 masih menjadi misteri. Siapa saja orang yang menembakkan pistol dari mulut hingga tengkuk para korban berlubang, siapa yang dengan membabi buta menembak hingga tubuh mayat penuh lubang dihujani peluru tidak juga diketahui. Namun, ada dugaan kalau aksi ini dilakukan oleh pasukan elit di bawah tangan Westerling.Pembantaian Takokak 1948 tetaplah menjadi horor bagi banyak pihak. Peristiwa berdarah yang dilakukan oleh Belanda ini bahkan nyaris tidak diketahui banyak orang. Pembantaian republiken oleh tentara Belanda di perkebunan teh Takokak di Puncak Bungah dan beberepa tempat lainnya seperti Cigunung Tugu dilakukan secara brutal. Bahkan, dalam genosida yang terjadi saat pasukan Siliwangi hijrah ke Jogjakarta pada tahun 1948 itu. Sebanyak 50 orang ditembaki setiap harinya (Tribun Jabar:2016).

Takokak daerah selatan, pasalnya dari ribuan pejuang yang bertempur melawan Belanda di medan tempur Gunung Tugu, hanya seorang yang selamat, yakni Bisri Arta Winata, sehingga masyarakat setempat menyebutnya jawara Jampang. Sebab daerah tersebut ketika zaman pemerintahan Hindia Belanda dimasukan kedalam zona Negeri Jampang bagian tengah sehingga disebut daerah Jampang Tengah yang dulunya masuk kedalam wilayah Kerajaan Cikundul (sekarang Cianjur). Menurut Cecep, putra sulung Bisri Arta Winata, tengkorak beserta tulang belulang tersebut di kumpulkan atas inisiatif ayahnya ketika menjabat sebagai Kepala Desa Takokak, karena ayahnya Yakni Bisri Atha Winata waktu zaman perjuangan sebagai tentara pejuang yang ikut bertempur melawan Belanda.Sejarah Pembantaian di Takokak Cianjur Selatan akan dibukukan.Sejarah pembantaian kaum republiken atau orang-orang yang berjuang membela republik Indonesia di Puncak Bungah, Kecamatan Takokak, Kabupaten Cianjur akan dibukukan. Hal tersebut mengemuka dalam Seminar Nasional bertema "Horor Takokak 1948" yang dihelat di Aula 
Markas Kepolisian Resor Cianjur, di Jalan Abdullah bin Nuh, Desa Nagrak, Kecamatan Cianjur tahun 2016. Hadir sebagai pembicara, Sejarawan Anhar Gonggong dan Wartawan Sejarah,Hendi Johari.Sejarawan, Anhar Gonggong menjelaskan, beberapa foto pada pameran foto perjuangan seusai Seminar Nasional bertema Horor Takokak 1948 di aula Mapolres Cianjur.

\subsection{Sisindiran Tradisi ala Masyarakat Takokak}

Takokak buah takekok,

Kacapiring reregean

Barudak ulah rarecok

Ieu kuring eukeur sasarean

Kini kini kuang kuang

Geutok geutok peupeundeyan

Nini nini keur mendeyang

Di bekok peperedeyan.

Aya roda na tanjakan

Katinggang ku pangpung jengkol

Aya randa gogoakan

Kapanggang ku hulu kon tongkol

Iitu gunung,ieu gunung

Gunungna gunung arjuna 
Itu pundung ieu pundung

pundungna bet duanana

Meuncit meri dina rakit

boboko wadah bakatul

Lain nyeri ku panyakit

Dina bujur aya bisul.

Jika masih gelap Shalatlah.

Jika masih tetap gelap maka bangunlah tengah malam dan Tahajudlah

Jika masih juga gelap,maka dekatilah orang tuamu dan ciumlah tangannya

Dan lalu katakanlah :" Emak isukan mayar listrik nya ameh caang"

Buah takokak buah takekok

Dina piring make sendok

Ari hayang kanu montok

Ari meunang anu dekok.

Anu Pondok nyogok

Anu panjang nyugak.

Sanes teu hoyong mondok

Paur sieun kacabak

Boneka cantik dari india 
Boneka cantik dari Mekah

Sangu saeutik ku sarerea

najan saeutik nu penting berkah.

Bersatu kita teguh

Bercerai kita runtuh

Rumasa jalmi teu gaduh

Hirup ge mung jadi buruh.

Ngadenge adan lohor

Waktuna sholat lohor

Kade gera solat tong molor

Bisi disebut jelema sakalor

Nelengneng kung-nelengneng kung

Geura gede geura jangkung

Geura sakola ka Bandung mugia jucung

Malar nulung ka Bapa sareng ka Indung

\section{Metode Penelitian}

Peneltian ini mengguanakan metode kualitatif sebagai prosedur penelitian, menghasilkan data-data naratif-deskriptif berupa cerita yang disajikan secara tulisan maupun lisan yang bersumber dari omongan orang perorang yang merupakan saksi sejarah. Pendekatan yang 
digunakan adalah metode deskriptif dengan pendekatan kualitatif.Pendekatan deskriptif karena penelitiannya memusatkan pemecahan masalah yang aktual, Surakhmad (2005:139), sedangkan Sugiyono (2006:216) mengemukakan bahwa: Penggunaan kualitatif karena penelitian berangkat dari kasus tertentu yang berada pada objek penelitian”.Berdasarkan kedua pendapat diatas maka penelitian ini merupakan studi kasus yang memfokuskan pada objek penelitaian pada kasus yang terjadi di Desa Takokak (kini Desa Pasawahan) Kecamatan Takokak Kabupaten Cianjur bagian selatan (RPH Sukabumi) pada kejadian horor akibat pembantaian peninggalan perang dunia ke dua melawan tentara Belanda yang memboncengi tentara NICA dan kenyakinan masyarakat pada kelahiran tokoh pemuda legendaris Sunda asal Takokak yang diyakini akan populer mendunia.Walaupun demikian, penelitian ini diperlukan yang tujuannya untuk lebih menggambarkan situasi dan kondisi objek penelitian. Menurut Bogdan dan Biklen (1990:30-34) Penelitian Kualitatif memiliki karakteristik sebagai berikut:

1) Mempunyai latar alami dengan sumber data langsung dan peristiwanya sebagai instrumen utama. 2) Bersifat deskriptif. 3) Memperhatikan proses ketimbang hasil.

4) Analisis data secara induktif. 5) Mengutamakan makna.Dari lima karakteristik lebih dikembangkan lagi oleh Nasution (1992:19) sebagai berikut: 1) Penelitian dilakukan dalam "natural setting”. 2) Penelitian sebagai "human instrument”. 3) Sangat deskriptif. 5) Mementingkan proses maupun produk. 6) Mencari makna. 7) Mengutanakan data kangsung atau "first hand". 8) Melakukan "transgulasi”. 9) Menonjolkan konteks.

10) Peneliti berkedudukan sama dengan orang yang diteliti. 11) Mengutamakan pandangan "emie". 12) Mengadakan verifikasi. 13) Menggunakan sampling yang purpositif.14) Menggunakan “audit trail”. 15) Melakukan partisipasi tanpa mengganggu. 16) Mengadakan analisis sejak awal. 17) Disain yang emergent.

Berdasarkan dua pendapat diatas, maka lebih memperjelas atau memperkuat bahwa metode yang digunakna dalam penelitian ini adalah metode deskriptif yang mengungkap kenyataan yang ada dilapangan serta dapat dipahami secara mendalam, sehingga pada akhirnya dapat diperoleh temuan penelitian.Penelitian yang menggunakan pendekatan kualitatif adalah sesuatu proses yang dimulai dari melihat, mengkaji dan menganalisis suatu fenomena dengan sedalam-dalamnya serta menemukan makna yang sangat berarti didalamnya.Untuk memperoleh karakteristik yang sesuai dan makna yang diharapkan dapat dikemukakan, maka teknik pengumpulan data yang digunakan melalui beberapa studi atau cara yaitu : Observasi, wawancara dan dokumentasi. 


\section{Hasil Penelitian}

Dari pengamatan yang peneliti lakukan selama studi di (Desa Takokak dulu) sekarang berubah menjadi Desa Pasawahan bahwa di Taman Makan Pahlawan Takokak sering di jadikan tempat upara hening cipta menjelang hari pramuka oleh pemerintah setempat sehingga seluruh siswa SLTP dan SLTA sekitar diwajibkan mengikuti upara yang biasanya dipimpin oleh Camat Takokak, hal ini untuk menanamkan jiwa patriot cinta bangsa dan negara sebagai pengamalan Panca Sila terhadap generasi muda.

Setelah dibacakan kisah pengorbanan pejuang bela bangsa dan negara oleh tak sedikit peserta upacara yang menangis terharu oleh sepak terjang para pejuang yang gugur di mendan perang, tampa penghargaan, tampa tanda jasa ikhlas karena Alloh SWT intinya pengamalan dari " hubbul wathan minal iman " artinya: Cinta tanah air sebagian dari iman.Setelah mengikuti upacara hening cipta di taman makam pahlawan tersebut sebagian siswa menginginkan mengisi kemerdekaan negeri ini, dengan terus serius belajar, sehingga kemerdekaan yang merupakan hasil perjuangan para pahlawan pendahulu ini tidak sia-sia.

Kisah perjuangan pahlawan Takokak menginpirasi para siswa peserta upacara untuk belajar tak tanggung-tangung agar dapat melanjutkan ke jenjang perguruan tinggi yang ada di kotakota besar di negeri ini agar dapat ikut serta membangun daerahnya.

Keadilan dan pemerataan pembangunan inprastruktur dan pembangunan ekonomi yang di contohkan Tomi Winata dalam pembangunan daerah menjadi sangat penting, untuk mengejar ketertinggalan dan keterbelakang karena Takokak selama ini, termasuk daerah terisolir di Kabupaten Cianjur, tetapi masuk Rumpun Pemangkuan Hutan (RPH) Sukabumi, lebih dekat dengan Sukabumi sehingga hasil produksi dari daerah ini tak ada kontribusinya ke Kabupaten Cianjur, melainkan ke Sukabumi. Di terminal Pasir Hayam milik Pemda Cianjur tak ada angkutan jurusan Takokak. Tapi di terminal Jubleg milik Pemkot Sukabumi tertulis jurusan Pasawahan-Takokak.

Ziarah ke Taman Makam Pahlawan adalah kegiatan masyarakat untuk menengok makam pahlawan yang telah gugur sahid bela bangsa dan negara, dengan cara berdo'a 
memohon ampunan bagi para pahlawan, karena mereka orang-orang soleh yang sanggup berkorban nyawa maupun harta benda untuk kemerdekaan generasinya, seperti kita yang masih hidup sebagai generasi penerus perjuangan sehingga generasinya mempunyai kewajiban mendo'akan mereka, dengan tahlil, tahmid dan istigfar yang barengi yasinan dan solawatan, untuk mengenang jasa para pahlawan.

\section{Simpulan}

Taman Makam Pahlawan (TMP) Takokak menjadi bukti sejarah, perjuangan para pahlawan yang gugur di medan juang. Menjadi pengingat bagi generasi penerus bangsa untuk mengenang jasa para pejuang kemerdekaan tanah air. Semangat juang patriot bela bangsa dan negara bisa ditularkan kepada para siswa melalui kisah sejarah perjuangan para pahlawan dengan menjadi Taman Makam Pahlawan Takokak sebagai media pembelajaran karakter melalui upara hening cipta setiap tanggal 14 Agustus pada setiap tahun menjelang upaca hari kemerdekaan Indonesia.

\section{Saran}

Keadilan dalam pemerataan pembangunan daerah perlu medapat perhatian dari pemerintah, agar tidak ada lagi daerah yang termasuk katagori daearah terisolir. Pembangunan mental spritual generasi muda perlu ditingkatkan dengan menamkan pendidikan karakter mealalui kisah jiwa-jiwa patriotisme para pahlawan pejuang kemerdekaan. Sehingga pelestarian nilai-nilai sejarah perjuangan para pahlawan menjadi sangat penting bagi generasi muda, pembangunan dan pemeliharaan taman makam-makam pahlawan harus memdapat perhatian dari pemerintah daerah maupun pusat, hal ini bisa menjadi media pembelajaran bagi para dosen-mahasiswa,guru-siswa dan masyarakat untuk media pendidikan karakter, wallahu a'lam. 


\section{Daftar Sumber:}

Pars Today, Langkah Kedua Revolusi (22-Habis, Jakarta

Facebook.com.Citizen6, Sudah pernah dengar tentang buah tekokak?, Jakarta

Putra De, Formulasi dan Aktivitas Anti Jamur Sediaan Krim M/A Ekstrak Etanol Buah Takokak (Solanum Torvum Swartz) Terhadap Candida Albicans

SA Wibowo, A Budiman, D Hartanti - JRST (Jurnal Riset Sains dan Teknologi), 2017

Wangga Candra Seta /Musahadah surya.co.id, Bisa Turunkan Asam Urat agar Kembali Normal, ini 11 Manfaat Takokak Tanaman Liar yang Disepelekan, surya.co.id, diakses 22 Mar 2020

Sindo News.com, Horor Takokak 1948: Sejarah yang Terlupakan, google.com

Tribun Jabar.Com,Targedi Takokak di Bukukan,Google.com

Tukang Cerita, Taman Makam Pahlawan Cigunung Tugu, Tragedi pembantaian di Takokak Cianjur, Google

Historia, Kisah Pembantaian di Takoakak,google.com

Aditya Prasanda,Kolase Hello sehat, Tokopedia surya.co.id, diakses 22 Mar 2020

De,Formulasi dan Aktivitas Anti Jamur Sediaan Krim M/A Ekstrak Etanol Buah Takokak (Solanum Torvum Swartz) Terhadap Candida Albicans

SA Wibowo, A Budiman, D Hartanti - JRST (Jurnal Riset Sains dan Teknologi), 2017 Id.Wikipedia. org

Tirto.id, Sejarah Persinggungan Tommy Winata dengan Tentara, google.com

Nugroho.Adi, Boombastis, Tragedi Takokak 1948, Pembantaian Rakyat Indonesia oleh Belanda yang Terlupan,google.com

Hendi Jo, Kisah Pembantaian di Cianjur Selatan, Historia 
Dian Nugraha Ramdani, Sejarah Pembantaian di Takokak Cianjur Selatan akan Dibukukan tribunjabar.id

https://jabar.tribunnews.com/2016/11/13/sejarah-pembantaian-di-takokak-cianjur-selatanakan-dibukukan. Tribunjabar.Co.Id

K.H.Muhamad Naban Husein, Seputar Kontroversi Imam Mahdi, Jakarta, Khairul Bayan

Allamah Muhammad Baqir Al-Majlisi, Riwayat Imam Mahdi pemimpin akhir zaman penegak keadilan di mika bumi,Lentera Jakarta

Kitab Al-Qur'an, Syamil Al-Qur'an, Kemenag RI, Jakarta 